\title{
EXPERIMENTAL INVESTIGATION ON CIRCULAR HOLLOW STEEL COLUMNS IN-FILLED WITH LIGHT WEIGHT CONCRETE (WITH \& WITHOUT GFRP) UNDER CYCLIC LOADING
}

\author{
Syed Murtuza ${ }^{1}$, N.S.Kumar ${ }^{2}$ \\ ${ }^{1}$ Post Graduate Student-Structural Engineering, ${ }^{2}$ Professor \& Director (R\&D-Civil Engg.), Department of Civil \\ Engineering, Ghousia College of Engineering, Ramanagara, Karnataka, India. \\ Syedmurtuza099@Gmail.com,drkumarns@gmail.com
}

\begin{abstract}
Composite Circular hollow Steel tubes with and without GFRP infill for three different grades of Light weight concrete are tested for ultimate load capacity and axial shortening, under Cyclic loading. Steel tubes are compared for different lengths, cross sections and thickness. Specimens were tested separately after adopting Taguchi's L9 (Latin Squares) Orthogonal array in order to save the initial experimental cost on number of specimens and experimental duration. Analysis was carried out using ANN (Artificial Neural Network) technique with the assistance of Mini Tab-a statistical soft tool. Comparison for predicted, experimental \& ANN output is obtained from linear regression plots. From this research study, it can be concluded that *Cross sectional area of steel tube has most significant effect on ultimate load carrying capacity, *as length of steel tube increased-load carrying capacity decreased \& *ANN modeling predicted acceptable results. Thus ANN tool can be utilized for predicting ultimate load carrying capacity for composite columns.
\end{abstract}

Keywords: Light weight concrete, GFRP, Artificial Neural Network, Linear Regression, Back propagation, orthogonal Array, Latin Squares

\section{INTRODUCTION}

Columns occupy a vital place in the structural system. Weakness or failure of a column destabilizes the entire structure. Strength \& ductility of steel columns need to be ensured through adequate strengthening, repair \& rehabilitation techniques to maintain adequate structural performance.
Recently, composite columns are finding a lot of usage for seismic resistance. In order to prevent shear failure of RC column resulting in storey collapse of building, it is necessary to make ductility of columns larger. Recently, most of building utilizes this Concrete Filled tubes (CFT) concept as primary for lateral load resisting frames. The concrete used for encasing the structural steel section not only enhances its strength \& stiffness, but also protects it from fire damages

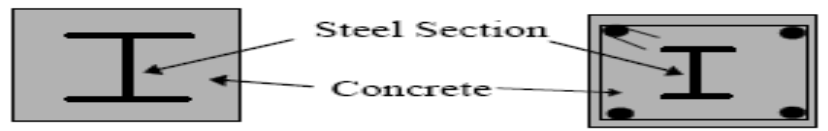

(a) encased strut

(b) erection column

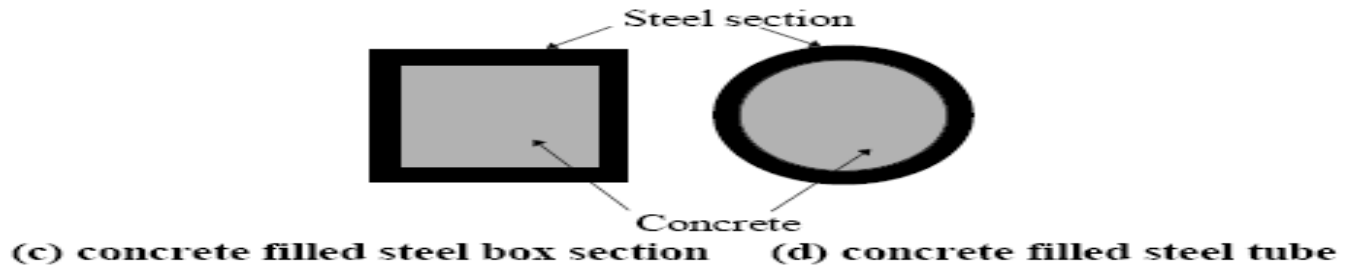

Fig1.Composite columns 
As the light weight concrete has lesser density $(300 \mathrm{~kg} / \mathrm{m} 3-$ $1850 \mathrm{~kg} / \mathrm{m} 3)$ than conventional concrete density $(2200 \mathrm{~kg} / \mathrm{m} 3-$ $2600 \mathrm{~kg} / \mathrm{m} 3$ ) it will have ease of handling, transporting \& reduced dead load in case of High rise building. Also its cellular structural arrangement helps in good insulation from heat \& sound.

In order to reveal the performance of CFT columns, specimens will be designed for axial compression cyclic loading. The Concrete that will be considered is Light weight concrete for infill in steel tubes.

Based on these factors, failure patterns \& influence of Light weight concrete slenderness ratio to Ultimate load ratio, Energy absorption capacity, \& Modulus of resilience are analyzed. Practical importance of this study is in the application of this system to "seismic resistance structures prone to earthquakes".

The experimental investigation focuses on modes of failure \& the most significant factor affecting the experiment with the help of Taghuchi's method. The equation can be generated to find the Ultimate load carrying capacity. Axial shortening \& ultimate stress carrying capacity of the column. Prediction of LCC can be done using NEURO Solutions: Artificial Neural Network Tool Box (MAT lab).

\section{ARTIFICIAL NEURAL NETWORK}

\subsection{Introduction}

One way of including specimen irregularities in the model is to use the results of the available experiments to predict the behavior of composite tubes subjected to different loading. Artificial Neural Network (ANN) is a technique that uses existing experimental data to predict the behavior of the same material under different testing conditions.

In the current work, the prediction of the load-carrying capacities for axially cyclic loaded Circular \& Square composite tubes is evaluated using ANN. To test the validity of using ANN in determining the crushing behavior of these tubes, the study will compare the predictions obtained to the experimental results using the neural network tool in MATLAB v7.12 (R2011a).

ANN have emerged as a useful concept from the field of artificial intelligence, and has been used successfully over the past decade in modeling engineering problems in general, and specifically those relating to the mechanism behavior of composite materials.

ANN generally consists of a number of layers: the layer where the patterns are applied is called input layer. This layer could typically include the properties of the composite material under consideration, its layup, the applied load, the tube aspect ratio etc. The layer where the output is obtained is the output layer which could, for example, contain the resulting deformation of this tube under the given loading conditions. In addition, there may be one or more layers between the input and output layers called hidden layers, which are so named because their outputs are not directly observable. The addition of hidden layers enables the network to extract high-order statistics which are particularly valuable when the size of the input is very large. Neurons in each layer are interconnected to preceding and subsequent layer neurons with each interconnection having an associated weight.

A training algorithm is commonly used to iteratively minimize a cost function with respect to the interconnection weights and neuron thresholds. The training process is terminated either when the Mean Square Error (MSE) between the observed data and the ANN outcomes for all elements in the training set has reached a pre-specified threshold or after the completion of a pre-specified number of learning epochs.

\subsection{Kolmogorov's Theorem}

Any continuous real-valued functions $\mathrm{f}(\mathrm{x} 1, \mathrm{x} 2, \ldots, \mathrm{xn})$ defined on $[0,1] \mathrm{n}, n \geq 2$, can be represented in the form
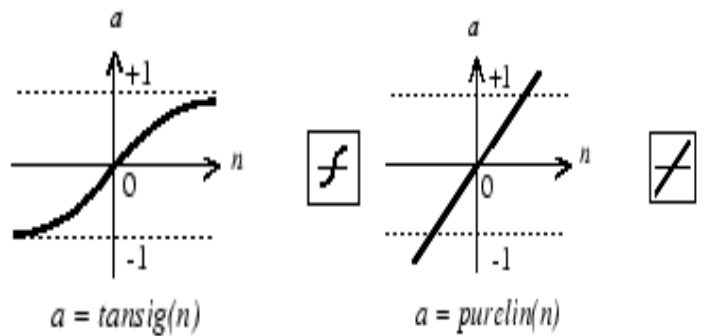

$\mathrm{f}(\mathrm{x} 1, \mathrm{x} 2, \ldots, \mathrm{xn})=\sum_{j=1}^{2 n+1} g_{j}\left(\sum_{i=1}^{n} \phi_{j}\left(x_{i}\right)\right)$

Fig2

Where the gj's are properly chosen continuous functions of one variable, and the ij's are continuous monotonically increasing functions independent of $f$.

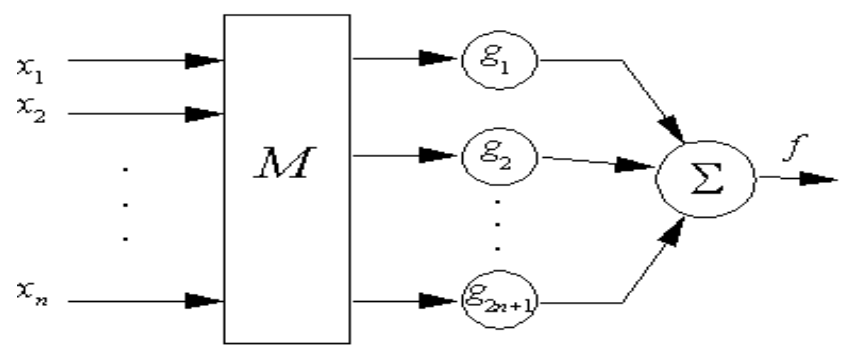

Fig2 (a): Block diagram of feed forward network 
Given any function $\phi: I^{n} \rightarrow R^{m}, \phi(x)=y$, where $\mathrm{I}$ is the closed unit interval $[0,1]$, can be implemented exactly by a three layer neural network with $n$ input nodes, $2 n+1$ hidden layer neurons and $\mathrm{m}$ output layer neurons, as represented in figure.

\subsection{Multilayer Neural Network Architecture}

\subsubsection{Neuron Model}

An elementary neuron with $\mathrm{R}$ inputs is shown below. Each input is weighted with an appropriate $w$. The sum of the weighted inputs and the bias forms the input to the transfer function f. Neurons can use any differentiable transfer function $\mathrm{f}$ to generate their output.

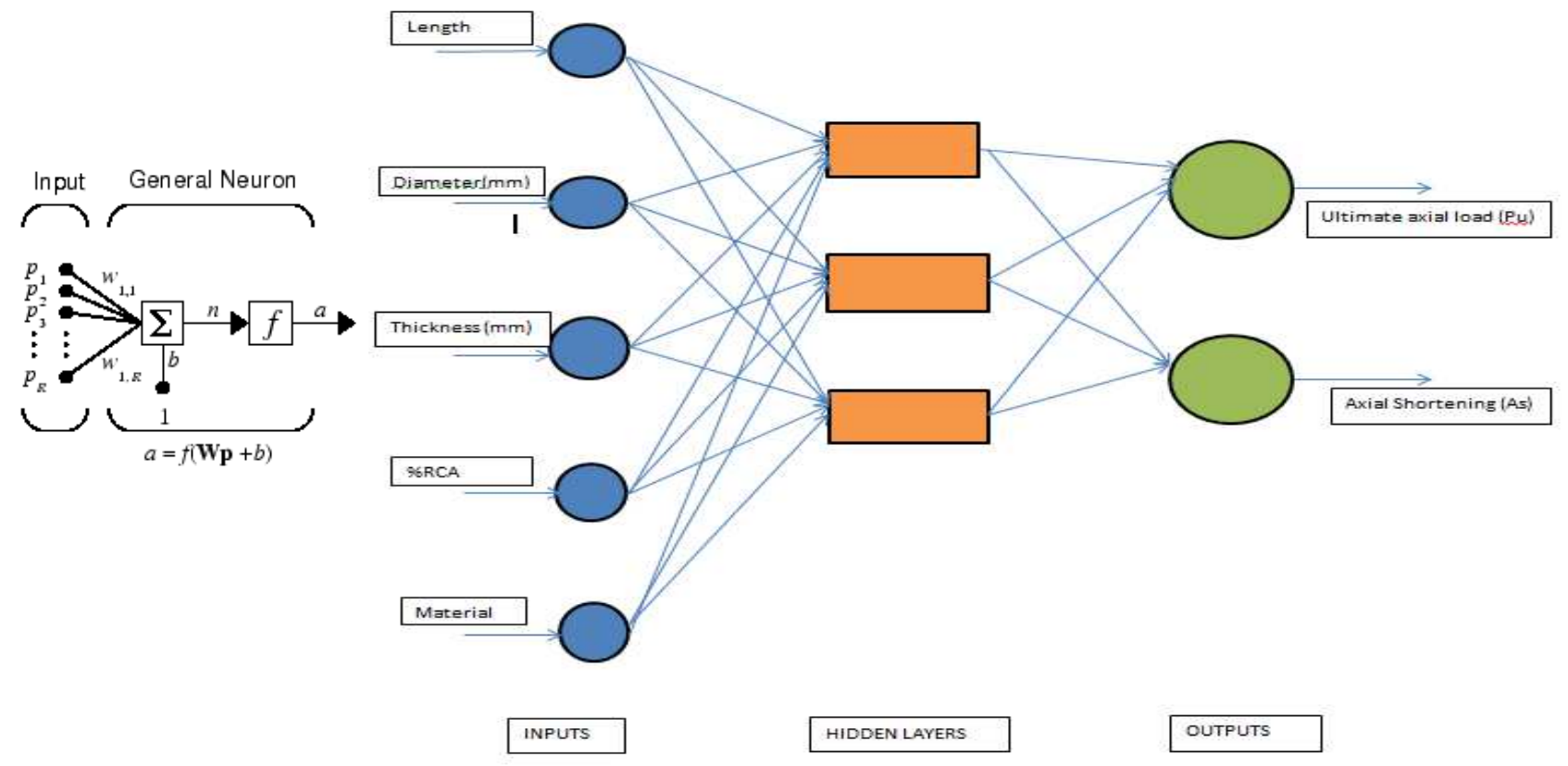

Fig3.Neuron model

Multilayer networks represented in figure3, can use the tansigmoid transfer function tansig as shown in figure2. Sigmoid output neurons are often used for pattern recognition problems, while linear output neurons are used for function fitting problems. The linear transfer function purelin as shown in figure2
Once the network weights and biases are initialized, the network is ready for training. The multilayer feedforward network can be trained for function approximation (nonlinear regression) or pattern recognition. The training process requires a set of examples of proper network behaviornetwork inputs $\mathrm{p}$ and target outputs $\mathrm{t}$.

\subsection{Train the Network}

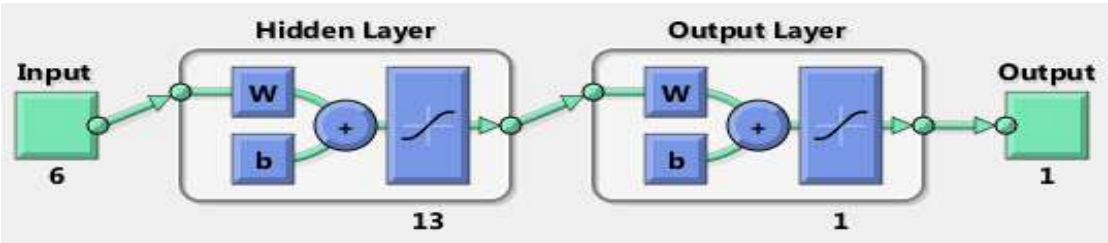


The process of training a neural network involves tuning the values of the weights and biases of the network to optimize network performance, as defined by the network performance function net.performFcn. The default performance function for feed forward networks is mean square error mse - the average squared error between the network outputs a and the target outputs t. It is defined as follows:

$$
F=m s e=\frac{1}{N} \sum_{i=1}^{N}\left(e_{i}\right)^{2}=\frac{1}{N} \sum_{i=1}^{N}\left(t_{i}-a_{i}\right)^{2}
$$

There are two different ways in which training can be implemented: incremental mode and batch mode. In incremental mode, the gradient is computed and the weights are updated after each input is applied to the network. In batch mode, all the inputs in the training set are applied to the network before the weights are updated. This chapter describes batch mode training with the train command. Incremental training with the adapt command is discussed in Incremental Training with adapt and in Adaptive Filters and Adaptive Training. For most problems, when using the Neural Network Toolbox software, batch training is significantly faster and produces smaller errors than incremental training. For training multilayer feed forward networks, any standard numerical optimization algorithm can be used to optimize the performance function, but there are a few key ones that have shown excellent performance for neural network training.

These optimization methods use either the gradient of the network performance with respect to the network weights, or the Jacobian of the network errors with respect to the weights. The gradient and the Jacobian are calculated using a technique called the back propagation algorithm, which involves performing computations backward through the network. The back propagation computation is derived using the chain rule of calculus.

\subsection{Network Properties}

The network type is feed forward back propagation. The training function is levenberg-marquardt algorithm. The performance function is mean square error. The transfer function is tan-sigmoidal and purelin (Fig.4).

\section{WORK FLOW}

The work flow for the general neural network design process has seven primary steps:
1. Collect data
2. Create the network
3. Configure the network
4. Initialize the weights and biases
5. Train the network
6. Validate the network (post-training analysis)
7. Use the network

\section{PREDICTION AND EXPERIMENTAL RESULTS}

Depicts the Linear-Sigmoidal (linsig) and Tan-Sigmoidal (tansig) functions used to build the model and train the network. The output is trained separately for both ultimate load and axial shortening load. Also the best values of prediction are obtained for 11 layers.

The experimental results which are obtained are given as the desired outputs to the feed forward back propagation network . These results were used to predict the output values and were in good agreement with the Kolmogorov's theorem. The output values and the deviations are obtained were tested and validated from 3 hidden layers to 14 hidden layers.

\section{METHODOLOGY}

\subsection{Taguchi's Method}

$>$ Taguchi started to develop new method to optimize the process of engineering experimentation

$>$ Taguchi's constructed a special set of Orthogonal Arrays to layout his experiments to study the effect of several control factors

$>$ In view of saving time \& material cost in experimentation lesser number of experiment is desired thus Taguchi's method is best suitable to find proper combination with minimum experimentations

\subsubsection{Steps involved in Taguchi's Design}

> A Taguchi's design or an Orthogonal array is a method of designing experiment that usually requires only a fraction of full factorial combinations

$>$ An orthogonal array means the design is balanced so that factor levels are weighted equally. because of this, each factor can be evaluated independently of all the other factors, so the effect of one factor does not influence the estimation of the other factor

$>$ In robust parameter deign you first choose factors \& their levels \& choose an orthogonal array appropriate for these control factors. The factors comprise the inner array

$>$ The experiment is carried out by running the complete set of noise factor setting at each combinations of control factors(at each run)

$>$ The response data from each run of the noise factor in the outer array are usually aligned in a row

$>$ Each column in the orthogonal array represent a specific factor with two or more levels

$>$ The following table displays the L8(2**7) Taguchi's design. L8 means 8runs $(2 * * 7)$ means 7 factors with 2 levels each

$>$ This array is orthogonal factor levels are weighted equally across the entire design. The table columns represent the control factors the table rows represent 
the runs \& each table cell represent the factor levels for that run.

\section{A Case Study}

For 3 Factors With 3 levels in General Design $=3^{3} \mathrm{X} 3\left(\mathrm{~L}^{\mathrm{F}} \mathrm{X} 3\right.$ Levels $)=81$

For 3 Factors with 3 levels in Taguchi's Design $=9$ Combinations X 3 Levels $=27$, Save $=66.66 \%$ For 4 Factors With 3 levels in General Design $=3^{4} \mathrm{X} 3\left(\mathrm{~L}^{\mathrm{F}}\right) \mathrm{X} 3$ Levels $=243$

For 3 Factors with 3 levels in Taguchi's Design

$=9$ Combinations X 3 Levels $=27$, Save $=88.89 \%$

\begin{tabular}{|c|c|c|c|c|}
\hline & & Columns & & \\
\hline Run & $\mathbf{1}$ & $\mathbf{2}$ & $\mathbf{3}$ & $\mathbf{4}$ \\
\hline $\mathbf{1}$ & $\mathbf{1}$ & $\mathbf{1}$ & $\mathbf{1}$ & $\mathbf{1}$ \\
\hline 2 & $\mathbf{1}$ & $\mathbf{2}$ & $\mathbf{2}$ & $\mathbf{2}$ \\
\hline 3 & $\mathbf{1}$ & $\mathbf{3}$ & $\mathbf{3}$ & $\mathbf{3}$ \\
\hline 4 & 2 & $\mathbf{1}$ & $\mathbf{2}$ & $\mathbf{3}$ \\
\hline 5 & 2 & 2 & 3 & $\mathbf{1}$ \\
\hline 6 & 2 & 3 & 1 & 2 \\
\hline 7 & 3 & 1 & 3 & 2 \\
\hline 8 & 3 & 2 & 1 & 3 \\
\hline 9 & 3 & 3 & 2 & 1 \\
\hline
\end{tabular}

\section{TYPICAL RESPONSE OF TAGUCHI'SANALYSIS FROM MINITAB 16}

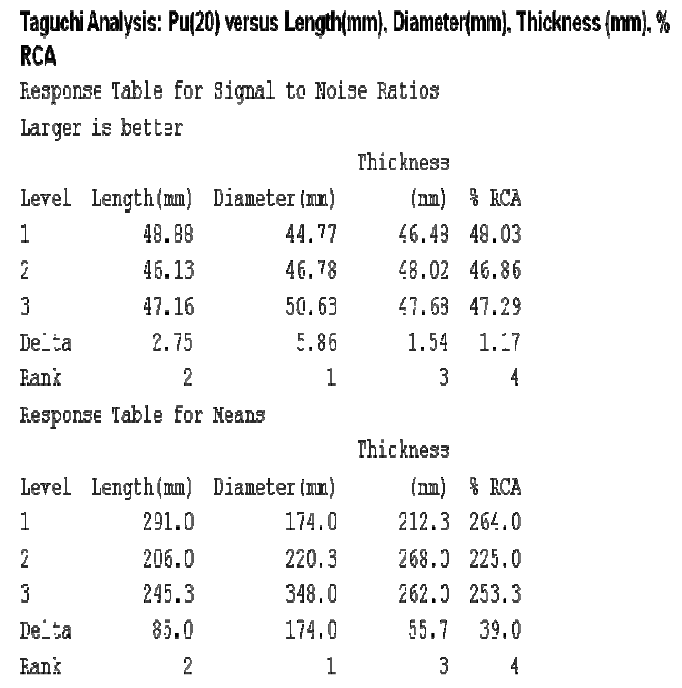

Taguchi's Design L9 (2**7)

\section{EQUIPMENTS \& EXPERIMENTAL PROGRAM}

$>$ Cutter ,Grinding machine, weighing machine Tamping rod 200ton Cyclic Loading Machine: to

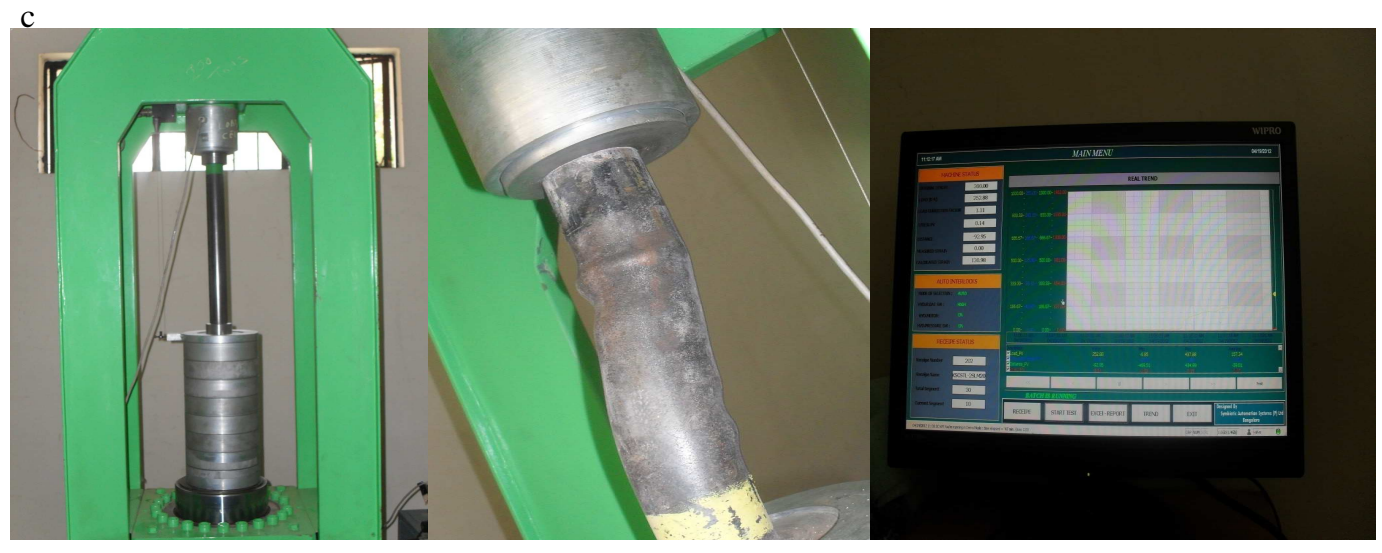

Fig4. 200T Cyclic Testing Machine 


\section{TESTS \& ANALYSIS:}

For Each Model, from every test following reading will recorded

\subsection{Graphical Analysis:}

Load vs Length \& Stress vs Strain
Load variation from load gauge in KN, Deflection in $\mathrm{mm} \&$ Stress in $\mathrm{N} / \mathrm{mm}^{2}$

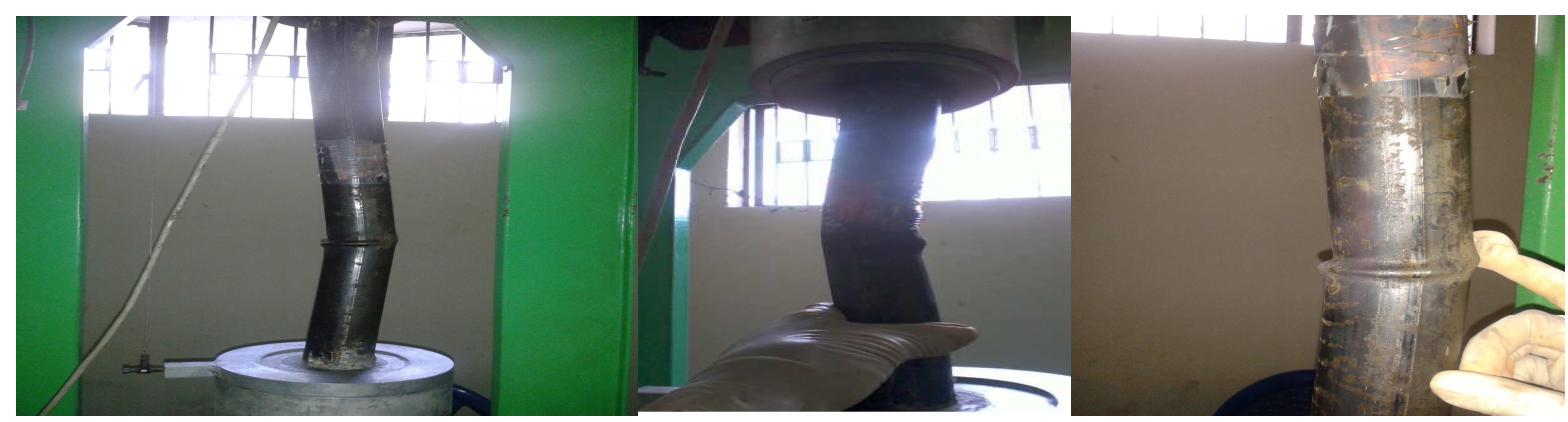

Fig5. Specimens failure after testing

Table1. Test Result values

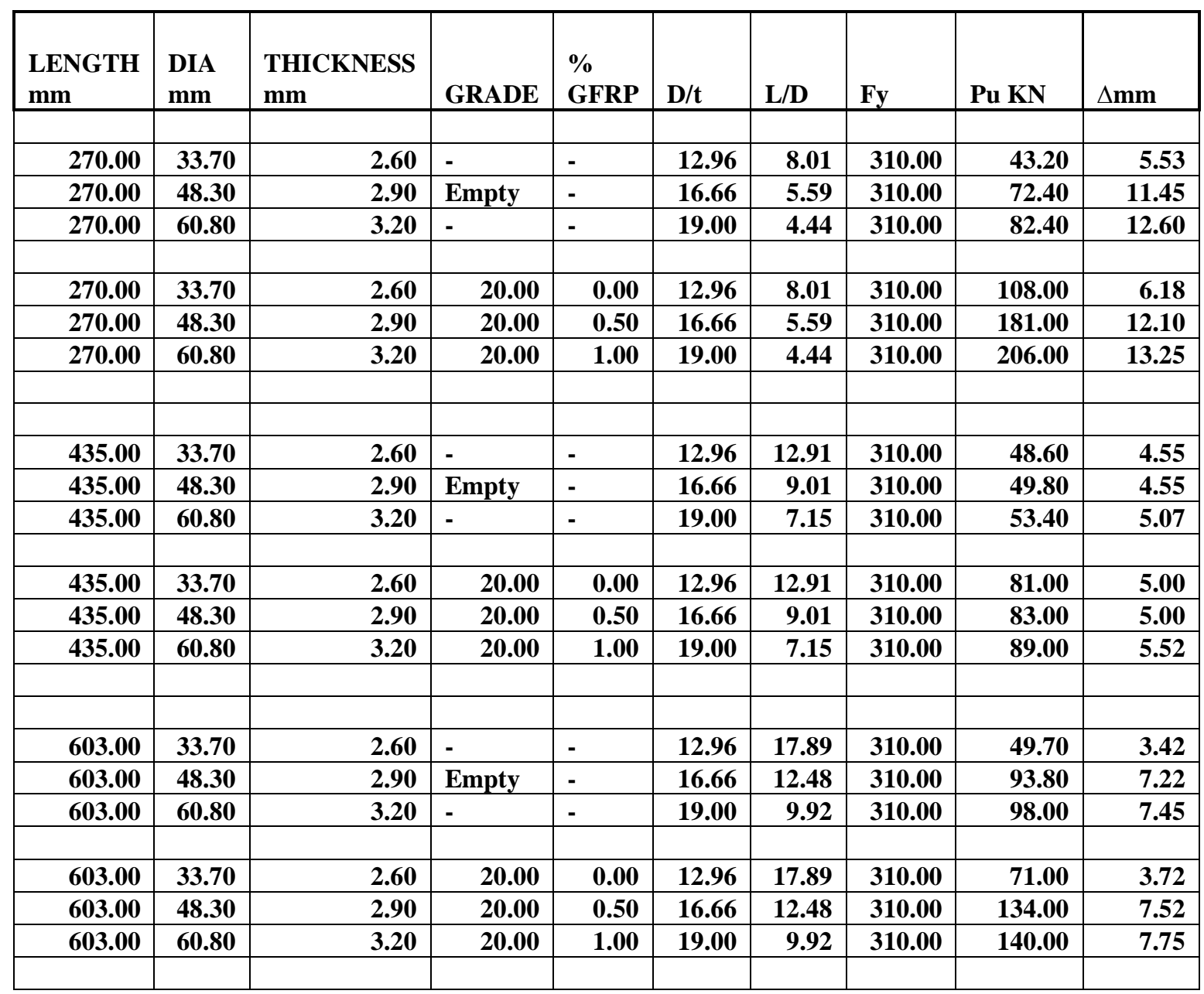


Table2. Comparison of $\mathrm{P}_{\text {th }}, \mathrm{P}_{\mathrm{uExp}} \& \mathrm{P}_{\mathrm{ANN}}$

\begin{tabular}{|c|c|c|c|c|c|c|c|c|c|c|}
\hline Pu KN & $\begin{array}{l}\text { ACI } \\
(1999)\end{array}$ & Put1/Pue & AS(1997) & Put1/Pue & $\begin{array}{l}\text { EC4 } \\
(1994)\end{array}$ & Put1/Pue & $\begin{array}{l}\text { Baiegt } \\
\text { al. }\end{array}$ & Put1/Pue & ANN & Put1/Pue \\
\hline & Put1 & & Put2 & & Put3 & & Put3 & & Put4 & \\
\hline 43.20 & 38.88 & 0.80 & 38.02 & 0.78 & 41.47 & 0.96 & 34.56 & 0.83 & 55.87 & 1.29 \\
\hline 72.40 & 65.16 & 0.90 & 63.71 & 0.83 & 69.50 & 0.86 & 57.92 & 0.79 & 74.74 & 1.03 \\
\hline 82.40 & 74.16 & 0.95 & 72.51 & 0.75 & 79.10 & 0.93 & 65.92 & 0.80 & 104.55 & 1.27 \\
\hline 108.00 & 97.20 & 0.78 & 95.04 & 0.76 & 103.68 & 0.75 & 86.40 & 0.76 & 96.64 & 0.89 \\
\hline 181.00 & 162.90 & 0.83 & 159.28 & 0.63 & 173.76 & 0.96 & 144.80 & 0.63 & 186.56 & 1.03 \\
\hline 206.00 & 185.40 & 0.90 & 181.28 & 0.59 & $\mathbf{1 9 7 . 7 6}$ & 0.68 & 164.80 & 0.59 & 187.48 & 0.91 \\
\hline & & & & & & & & & & \\
\hline 48.60 & 43.74 & 0.69 & 42.77 & 0.78 & 46.66 & 0.79 & 38.88 & 0.83 & 42.78 & 0.88 \\
\hline 49.80 & 44.82 & 0.76 & 43.82 & 0.83 & 47.81 & 0.91 & 39.84 & 0.79 & 65.58 & 1.32 \\
\hline $\begin{array}{l}53.40 \\
\end{array}$ & 48.06 & 0.90 & 46.99 & 0.52 & 51.26 & 0.67 & 42.72 & 0.80 & 81.14 & 1.52 \\
\hline 81.00 & 72.90 & 0.78 & 71.28 & 0.58 & 77.76 & 0.53 & 64.80 & 0.48 & 72.11 & 0.89 \\
\hline 83.00 & 74.70 & 0.83 & 73.04 & 0.34 & 79.68 & 0.97 & 66.40 & 0.69 & 64.07 & 0.77 \\
\hline 89.00 & 80.10 & 0.90 & 78.32 & 0.86 & 85.44 & 0.91 & 71.20 & 0.73 & 104.28 & 1.17 \\
\hline & & & & & & & & & & \\
\hline 49.70 & 44.73 & 0.58 & 43.74 & 0.69 & 47.71 & 0.69 & 39.76 & 0.59 & 80.46 & 1.62 \\
\hline 93.80 & 84.42 & 0.34 & 82.54 & 0.76 & 90.05 & 0.87 & 75.04 & 0.78 & 150.00 & 1.60 \\
\hline 98.00 & 88.20 & 0.86 & 86.24 & 0.39 & 94.08 & 0.96 & 78.40 & 0.64 & 109.72 & 1.12 \\
\hline & & & & & & & & & & \\
\hline 71.00 & 63.90 & 0.69 & 62.48 & 0.58 & 68.16 & 0.93 & 56.80 & 0.83 & 96.65 & 1.36 \\
\hline 134.00 & 120.60 & 0.76 & 117.92 & 0.34 & 128.64 & 0.83 & $\mathbf{1 0 7 . 2 0}$ & 0.79 & 127.96 & 0.95 \\
\hline 140.00 & 126.00 & 0.90 & 123.20 & 0.86 & 134.40 & 0.98 & 112.00 & 0.80 & 112.44 & 0.80 \\
\hline & & & & & & & & & & \\
\hline AVG & & 0.79 & & 0.66 & & 0.84 & & 0.73 & & 1.14 \\
\hline
\end{tabular}

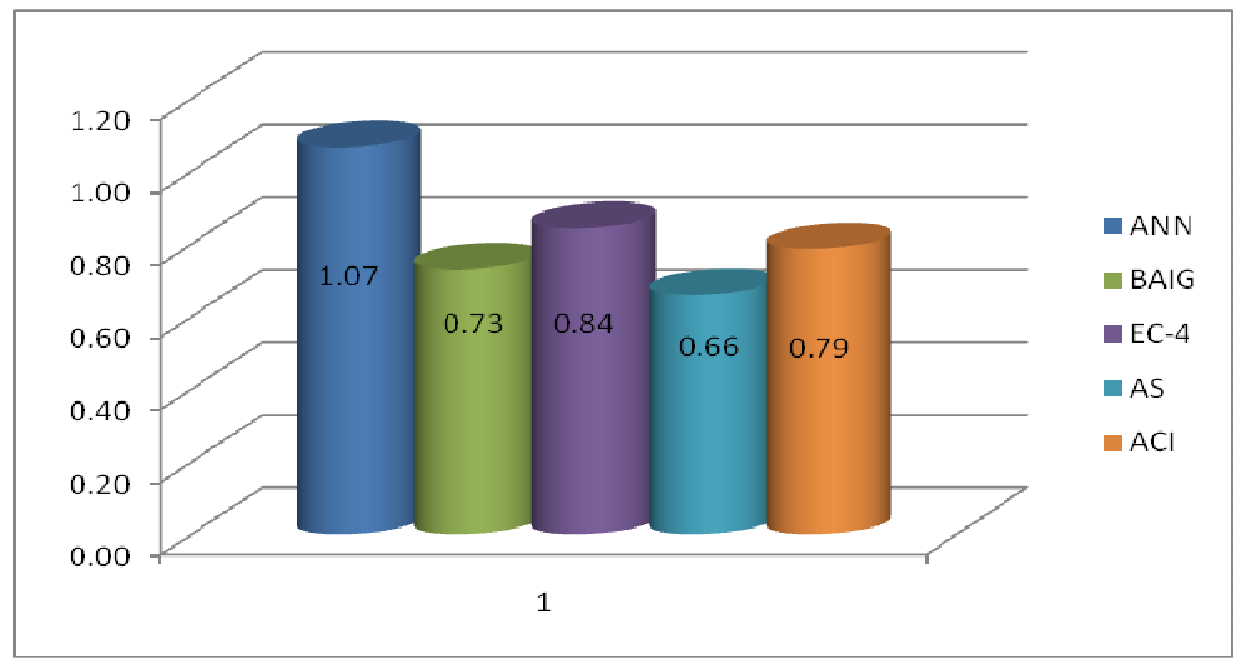

Figure6. Comparison of $\mathrm{P}_{\mathrm{th}}, \mathrm{P}_{\mathrm{uExp}} \& \mathrm{P}_{\mathrm{ANN}}$ 

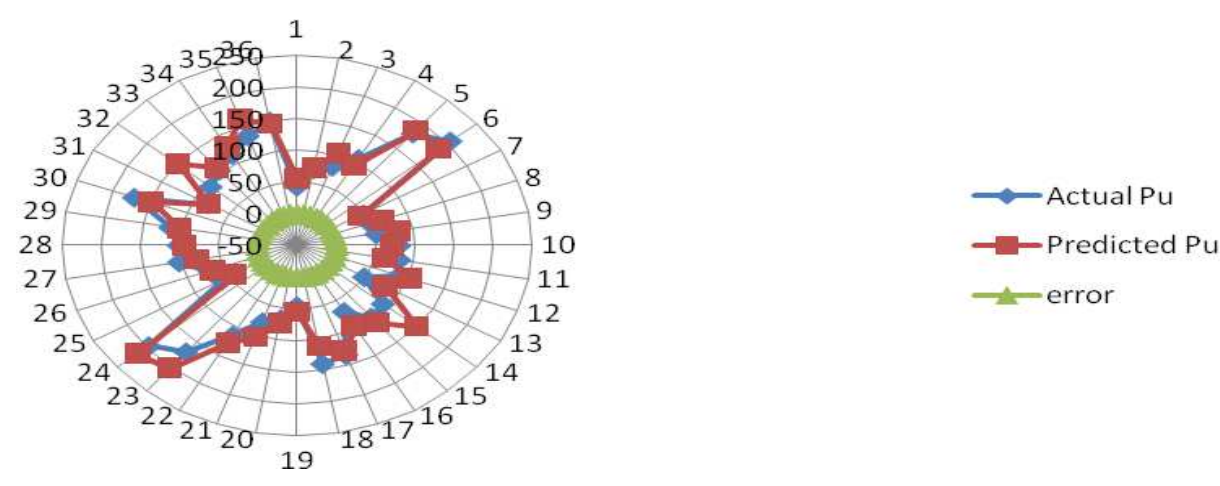

Figure7. Error b/w Actual $\mathrm{P}_{\mathrm{u}} \& \mathrm{P}_{\mathrm{ANN}}$ Values

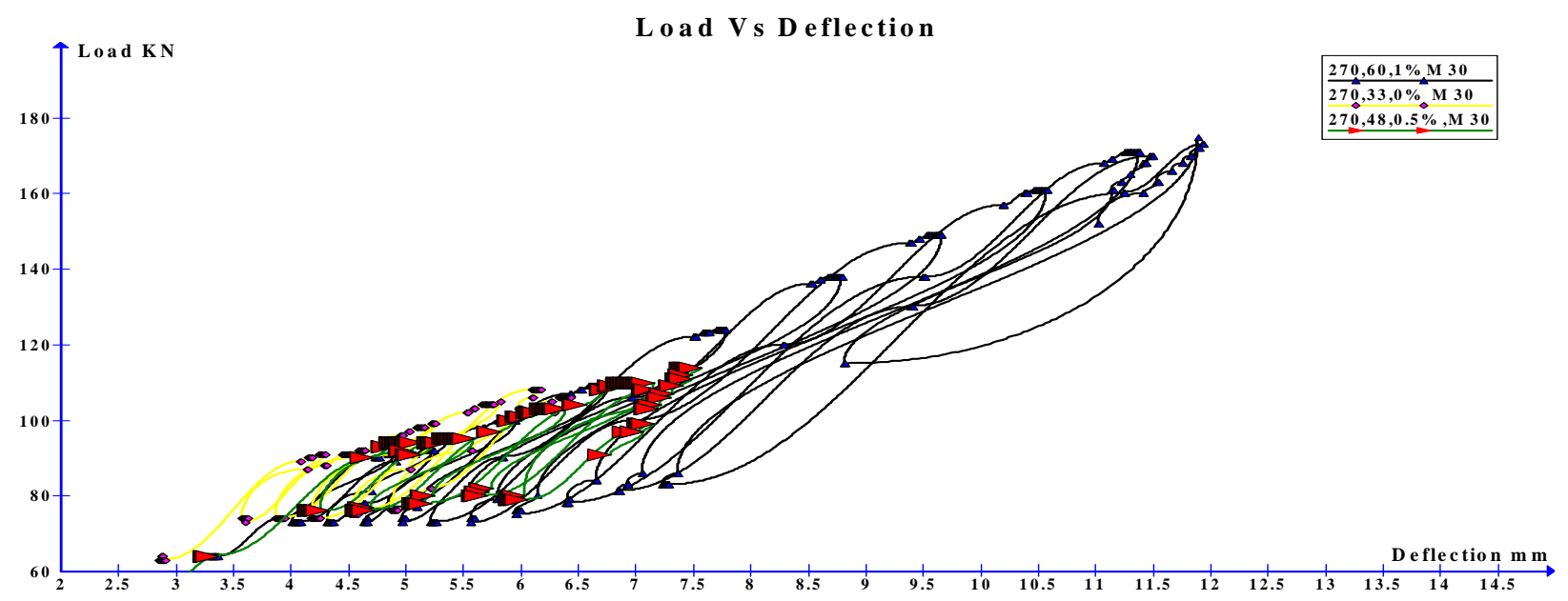

Figure8. Load V/s Deflection

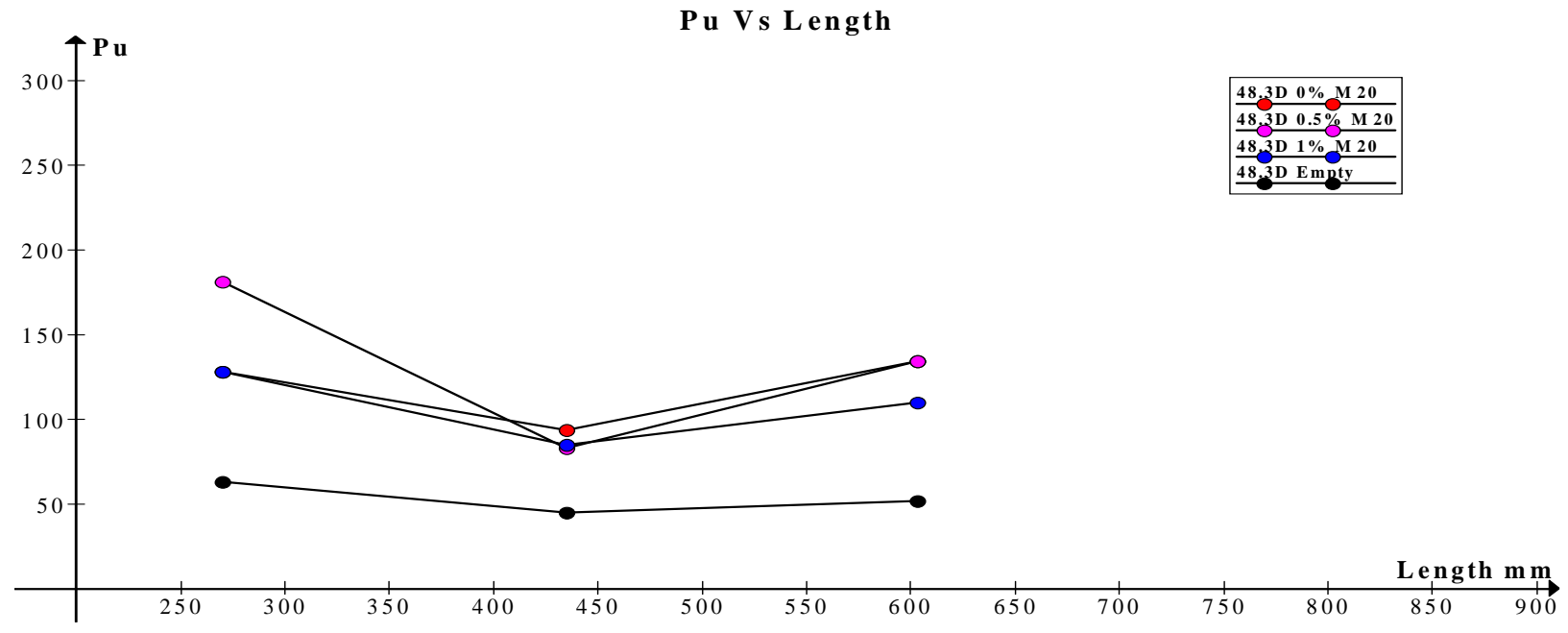

Figure9 Load V/s Length 


\begin{tabular}{|l|l|}
\hline Specimen grade and Loading & Axial Shortening \\
\hline M20 Cyclic Loading & Diameter \\
\hline M30 Cyclic Loading & Diameter \\
\hline M40 Cyclic Loading & Thickness \\
\hline M20 Sustained Loading & Diameter \\
\hline M30 Sustained Loading & Thickness \\
\hline
\end{tabular}

\subsection{Verification of Taguchi's Method}

After conducting the initial nine experiments (each in triplicate trial is $9 \times 3=27$ ), linear regression models are developed for all grade of infill \& regression models of M20, M30\& M40 are shown below

$>\mathrm{Pu}(20)=-270-0.191 \quad$ Length $(\mathrm{mm})+9.86$ Diameter $(\mathrm{mm})+34.3$ Thickness $(\mathrm{mm})-0.107 \%$ GFRP

$>\mathrm{Pu}(30)=-307-0.206$ Length $(\mathrm{mm})+12.4$ Diameter $(\mathrm{mm})+19.3$ Thickness $(\mathrm{mm})-0.263 \%$ GFRP

$>\mathrm{Pu}(40)=-243-0.215 \quad$ Length $(\mathrm{mm})+11.7$ Diameter $(\mathrm{mm})+10.7$ Thickness $(\mathrm{mm}) \quad-0.133 \%$ GFRP

$>$ As $(20)=83.3-0.0096$ Length $(\mathrm{mm})+0.660$ Diameter $(\mathrm{mm})$ - 3.10 Thickness (mm) - $0.0039 \%$ GFRP

$>\mathrm{As}(30)=296-0.175 \operatorname{Length}(\mathrm{mm})-0.72 \operatorname{Diameter}(\mathrm{mm})$ - 18.9 Thickness (mm) - $0.047 \%$ GFRP

$>\mathrm{AS}(40)=88.7-0.0195 \quad$ Length $(\mathrm{mm})+0.261$ Diameter $(\mathrm{mm})+1.60$ Thickness $(\mathrm{mm})+0.0203$ GFRP

\section{CONCLUSIONS}

$>$ Taguchi Method found to be best for selection of specimens \& with the help of Min tab. From time series plot we observe that ultimate axial load carrying capacity and axial shortening of column was predicted very well.

$>$ Maximum Load Carrying Capacity can be for the $270 \mathrm{~mm}$ length, 60.3mmDia, 3.2mm Thickness and 1\% GFRP.

$>$ Minimum Axial Shortening is obtained be for the $600 \mathrm{~mm}$ length, $60.3 \mathrm{mmDia}, 3.2 \mathrm{~mm}$ Thickness and 1\% GFRP.

$>$ Parametric optimization and factors influencing the response can be determined

$>$ There is huge saving of cost and time in experimental work ie $88 \%$ of Saving for our Experimental work

$>$ From Taguchi Analysis for maximum Axial Shortening Carrying Capacity From Response of means and response table of S/N Ratios the predominate factors are

$>$ Practical application of this study is in the application of this system to "Seismic resistance structures prone to earthquake. Also taking the advantage of light weight concrete as a in-filled which has density $(300 \mathrm{~kg} / \mathrm{m} 3-$ $1850 \mathrm{~kg} / \mathrm{m} 3)$ \& its cellular structure provide good thermal insulation \& reduced dead load in case of high rise building .

$>$ From load v/s length it is found that as length increases load carrying capacity decreases.
From Load v/s deflection ductility of composite columns found to be more comparing to empty tube.

$>$ Artificial neural network predicted good results

\section{REFERENCES}

[1] Shams M saadeghavaziri MA. State of art concrete filled tubular columns ACI Struct J1997; 94(5)558-7.

[2] Liu Dalin, Gho wie- Min, Yuan Jie. Ultimate capacity of high-strength rectangular concrete-filled steel hollow section stub columns. J constr steel res 2003;59:1499515

[3] Elremaily Ahmed, Azizinamini Atorod. Behavior and strength of circular concrete-filled tube columns. J constr steel res 2002;58:1567-91.

[4] Tao zhong, Han Lin-Hai, Wang Dong-ye. Strength and ductility of stiffened thin -walled hollow steel structural stub columns filled with concrete. Thin Walled struct 2008;46:1113-28.

[5] IS 10262-1982.India standard recommended guidelines for concrete mix design. Bureau of Indian Standards, New Delhi, India.

[6] Eurocode 4. Design of composite steel and concrete structures, part 1.1: general rules for buildings. Commission of European communities, British standards institution;1994

[7] metal matrix compositesJournal of the Brazilian Society of Mechanical Sciences and Engineeringversion ISSN 1678-5878

[8] Schneider SP. Axially loaded concrete-filled steel tubes.J struct eng, ASCE 1998;124(10):1125-38.

[9] D.S.Ramachandra Murthy,et.al., "Seismic resistance of the reinforced concrete beam-column joints with TMT and CRS bars", ICI Journal, vol.1,July-Sep.2000,no.2, pp.19-26.

[10] A Case Study"* "Experimental investigation of CFT under Monotonic Loading" was carried out by B.E students of Ghou sia College of Engineering, Ramanagaram. Mr. Sameer Simha,MsKavya KS,Mr.Gowtham S Gowda\& Mr.Arun Kumar. 